\section{NOTES ON SULPHONAL.}

BY HENRY SUTHERLAND, M.D., PHYSICIAN TO THE ST. GEORGE'S (HANOVER-SQUARE) DISPENSARY.

AFTER repeated trials of sulphonal in various forms of insanity, I have come to the conclusion that in chronic cases associated with recurrent attacks of excitement sulphonal is a most valuable remedial agent, producing sleep, not only on one occasion, but also on two or three nights following its administration. In this form of insanity it also considerably allays excitement during the day, although it may have been given once only as a soporific at bedtime. My experience of its advantages in other forms of mental disease (and especially in continued chronic mania, as opposed to recurrent chronic mania) is less satisfactory.

I. In chronic mania with recurrent attacks of excitement the good effects of sulphonal are very conspicuous.

CASE 1.--Mr. B. R-, aged forty-seven. Usually very quiet. Has attacks of noisy excitement and sleepless nights at irregular intervals. Bromide and chloral in large doses have been given with but slight effect. One dose of thirty grains of sulphonal quiets him at once; not only during the night on which it is taken, but also on the two or three nights following. Strangely, while at the seaside this dose produced little or no effect.

CASE 2.-Mr. L. C-_-, aged seventy. Recurrent mania, with restless nights. Owing to advanced age bromide and chloral do not seem to be indicated. Takes twenty grains of sulphonal now habitually every al ternate night, the result being a long refreshing sleep with two or three quiet nights to follow.

CASE 3.-Mrs. G. M-, aged sixty-seven. Recurrent mania with depression between the attacks. Formerly she was very violent. Bromide, chloral, opium, and all sedatives failed to quiet her until antimony was tried, which had a good effect. Owing to advancing age and the fact that she has a dilated heart, it is thought dangerous to prescribe this remedy any longer. The symptoms, too, are now limited to using bad language and shouting, her attacks upon her attendants being discontinued. Fifteen grains only of sulphonal produced sleep on one night and again on the two nights following, and also a condition of quietude during the day. If not given every three days sleep leaves her and the excitement returns.

II. In chronic mania with continuous, unbroken excitement the effects of sulphonal are uncertain, and the maniacal symptoms seem to be increased during the day.

CASE 4.-Mr. C. R_-, aged thirty-four. Chronic mania (folie circulaire). Continually in a restless condition. Very dirty. Sleeps badly. Bromide and chloral have failed. One dose of thirty grains of sulphonal quieted him for a short time, but subsequent doses have had little or no effect.

CASE 5.-Miss B. D-, aged twenty three. Chronic mania. Never talks. Attacks the attendants impulsively. Sleeps very badly. Bromide produces rash. Sulphonal was tried (fifteen to thirty grains). On some nights she sleeps badly after sulphonal, and on other nights she sleeps well without it. With one exception only she was always more excited during the day after taking this sedative.

CASE 6.-Miss G. A—, aged fifty-two. Chronic mania, with never-ceasing restlessness and moaning. Began with twenty grains. Very stupid the day after this small dose. Slept well that one night, but not well subsequently. Dose increased to thirty grains, and on one occasion to fifty grains. She had no sleep after this large dose. Coördination was much affected. She rolled about in walking next day as if intoxicated.

CASE 7.-Miss G. W-, aged thirty-four. Chronic mania, with violence. Once slept nine hours after fifteen grains; on another occasion slept only two hours after twenty grains. Thirty grains of sulphonal sometimes produce sleep, sometimes have no effect. More excited during the day after taking the drug.

III. Effects of sulphonal in other Jorms of insanity.

CASE 8.-Mr. G. T-_, aged forty. Organic dementia, with hemiplegia. Very restless at night. Ten grains were given on one occasion with good effect. Being almost moribund, it is not thought advisable to continue the sedative.
IV. Incipient general paralysis, with very restless nights. CASE 9.-This patient derived benefit from thirty grains of sulphonal taken one night; also on the following two nights. Took several doses, and it has never failed.

V. Sane patient. Bad effects of sulphonal.

CASE 10.-W. B-, aged twenty-six. Night watch. Being new to the duty was unable to sleep by day. Took thirty grains of sulphonal. Slept eight or nine hours, but woke with a splitting headache. Thirty grains were tried on a second occasion with the same result.

VI. Sane patient. Good effects of sulphonal.

CASE 11.-This patient had a severe cold, with high temperature and sleepless nights. Antipyrin was taken during the day. Sulphonal (thirty grains) taken nightly produced excellent effects.

\section{Modes of Administration.}

After a repeated series of experiments I find sulphonal (in the proportion of thirty grains to one ounce of the menstruum) to be insoluble in cold water, brandy, sherry, ether, nitric acid, and liquor potassa. It is soluble in all these menstrua if boiling, but rapidly precipitates on cooling. It remains in solution far longer in brandy than any other liquid, and might be advantageously given by mixing boiling brandy with sulphonal in solution with hot beeftea, which is, however, a nauseous compound. It is difficult to dissolve in any case, and is more appropriately administered in the solid form, as it is quite tasteless ; nor does it burn the mouth as chloral does. It mav be conveniently given as follows:- $(\alpha)$ In warm beatenup eggs and milk; but the mixture must be well stirred before taken, or the drug will sink to the bottom. (b) In stewed fruit, with plenty of juice and white pounded sugar. (c) In milk puddings, either mixed with the pudding or with the sugar given with the pudding. (It has been tried in the gravy of meat, but is usually detected by the patient.) (d) In hot soup it is freely soluble, but the mixture must not be allowed to cool, or the drug will be found as a deposit at the bottom of the basin. (e) May be given also between two thin slices of bread-and-butter. A few grains of calomel may be added if necessary. Both drugs are tasteless. $(f)$ Might be given made up in a confection or in jam. $(g)$ With patients who do not refuse medicine the following formula may be used:- Sulphonal, $20 \mathrm{gr}$. ; pulv. tragacanth., $2^{0} \mathrm{gr}$. ; syrup. aurantii, $1 \mathrm{dr}$.; aquam ad $1 \mathrm{oz}$. The draught to be well shaken. (This formula is from Mr. E. T. Hall.)

\section{Conclusions.}

Sulphonal is a most valuable sedative in chronic insanity with recurrent attacks of excitement. It is, however, somewbat curious that, in recurrent excitement, the drug should prove so efficacious, whilst in continued excitenent (a form strongly resembling recurrent excitement) the $\epsilon$ fiests should be not only slightly marked but also apparently in jurious, by increasing the state of excitement in the patient on the following day. The lesson to be learnt from a suidy of the effects of sulphonal is that we ought to endeavour to ascertain in what form of alienation and under what particular conditions this or that individual drug is indicated. It is only by the application of one special remedy to a special symptom, or by a mixture of remedies appropriately chosen to a mixture of symptoms, that we can hope to gain any advance in the empirical treatment of insanity.

\section{SULPHONAL IN THE INSOMNIA OF TYPHUS.}

\section{By C. KNOX BOND,}

RESIDEXT MEDICAL OHICER, CITY FOSPITAL, SOUTIS IXVERPOOL.

A DRUG which will induce sleep in typhus fever (and yet avoid the tendency of some other hypnotics, notably opiates, to cause stupor and allied conditions leading $u_{b}>$ to coma), and further which can be given with confidence when these conditions are already to some extent present, substituting natural sleep for semi-stupor, wonld be of extreme value in the treatment of this disease. Sulphonal could scarcely be submitted to a more severe test as regards its harmless, sleep-causing powers than when tried in this direction, and in estimating its worth the following analysis of notes of twenty-three cases in which sleeplessness occurred as a prominent symptom among a total of serenty- 
six cases of typhus treated in the City Hospital, South Liverpool, during the past twelve months, may be of service. The insoluble and tasteless powder was given in thirty-grain doses mixed with beef-tea, warm milk, or whisky-andwater at 8 or 8.30 P.M. The largest amount given was ninety grains in three doses divided over a pericd of six hours. The typhus was of a severe type, diarrhoea being present in a laige number of cases, and exerting its influence in this as in all febrile disorders, as perhaps the most pernicious symptom to be dealt with, the frequent ochreyyellow alkaline "typhoid" stools, now almost rare in our enteric wards, reappearing amongst these typhus cases. In all the cases from which these notes were taken the spotted abundant eruption of typhus was present and unmistakable.

In nearly all cases sleeplessness harl been present for a period of twenty -four hours and upwards before the drug was lirst given, and was associated with active delirium, and an estimate of its effect as a sleep inducer cannot be separated from consideration of $i$ ts calming effect on delirium ; in the few cases in which the drug had no immediate effect in causing sleep it was noted that the delirium was lessened and that the patient became quieter. After the sleep of sulphonal it was usual to find patients previously violently delirious had become quieter and more rational. Only in one case was it noted that the patient had become " more violently delirions and restless" after the drug; on the dose being repeated he still remained restless and delirious for three hours, then became quiet and had sound sleep for five hours, awaking quiet and sensible. This man had been a heavy drinker, consequently the delirium was intractable. The time before sleep was induced was commonly half an hour, the shortest tineless than ten minutes, the longest three hours (the above case, and a case of maniacal delirium after abortion), and four hours (one case of pneumonia in which the next night sleep followed in half an hour). The drug failed in two cases to produce sleep; in one it was administered in the afternoon, in a case in which typhus and typhoid were both present, with severe diarrhcea and delirium, opium in considerable doses also failed; in the other the failure was due in great measure to the fact that the patient was under partial restraint, owing to violence of delirium, chloral also failing from the same cause. In five cases the first dose given failed, and bad to be repeated, sleep following second dose, given four hours later; in four cases, in one a powerful man very violently delirious, and who had recently drunk hard, sleep did not ensue until after the third dose on two occasions, the three doses being given in one instance within nine hours, and on the following night within six hours. This man was afterwards quiet and tractable, and made a good recovery. The duration of the sleep averaged from three to five hours, the longest being twelve hours, the shortest an hour and a half. The character of the sleep in the majority of cases was sound natural sleep, from which the patients could easily be roused for nourishment, quickly dozing off again. In a few moaning and slight uneasiness were noted; in many the effect lasted during the following day, the patients being drowsy and sleeping at intervals. The patient's own sensations were seldom obtainable, owing to the mental condition. Equally no suggestion was present in their minds as to the anticipated effect of the powder, but the more rational always expressed themselves as feeling better after sleep; none suffered from headache. In a large proportion of cases pulmonary congestion was severe ; in a minority pneumonia was present. These cases exhibited no increase of dyspncea or lividity after taking the drug; in no case was the pulse found to be altered in foree, volume, or rhythm. Dryness of either the tongue or skin was not increased. Moistening of the edges of the tongue and sweating were occasionally noted on the day after the powder was given. Any possble effect of the drug as a factor in the causation of the liarrboa was carefully negatived. The difficulties in the way of obtaining evidence as to any effect on secretion of urine appeared insuperable as separate from those of the disease itself, albuminuria being usually present on admission. Diminution, increase, retention, and incontinence of urine were fairly common symptoms.

In only one case was there any suggestion of possible ill-effect of the drug. It was a man aged twenty-two years, in whom from the first there was evidence of profound heart failure, rapid cardiac dilatation, associated with petechial rash and alburninuria in excess; the whole condition pointing to impending collapse, which actually occurred at the time of the crisis. The temperature fell in a few hours from $104^{\circ}$ to normal. Death ensued five days later, on the eighteenth day. Sulphonal had been given twice the previous night; but on careful examination of the facts of the case it would not seem to have contributed towards the fatal result, which was due to collapse at the time of the expected crisis. In this case diarrhoea, by far the most fatal factor in this series of cases, was present almost throughout the illness.

As tar as these cases can be fairly said to prove anything, they indicate clearly that sulphonal is of very great value as a means of inducing sleep in typhus, and remarkably free from attendant disadvantages. With the few exceptions above noted, easy natural sleep was with certainty induced within a reasonable time, and the condition was again easily established on subsequent occasions. The patients benefited by the rest, and in no case suffered from the remedy. I have to thank Dr. Wm. Irvine, under whose care these cases were admitted, for permission to publish these notes.

\section{A CASE OF}

INTRA-PERITONEAL H EMATOCELE DUE TO RUPTURE OF A TUBAL PREGNANCY TREATED BY ABDOMINAL SECTION, AND REMOVAL OF THE RUPTURED TUBE.

\section{BY LAWSON TAIT, F.R.C.S., \&c.}

NoTHING could offer a more striking -indeed I may say a more startling - contrast than the case I am now about to narrate when compared with the case narrated in TrE LANCET of Aug. 24th by Mr. T. N. Thomas of Leicester. On the morning of Aug. 20th, at 11 o'clock, Dr. Thomas Nelson, of this city, walked into my consulting-room and told me that he had seen, the night before, a married woman of twenty-six, who had complained of sudden access of pain and discomfort in the lower part of the abdomen. She had rapidly got worse, and when seen by him on the morning in question she was found in a condition of collapse, acute anæmia, and all the symptoms of internal abdominal hæmorrhage, and the one point in the history which gave him a clue to the nature of the case was that she had gone two weeks past her time of expected menstruation. He made the diagnosis of ruptured tubal pregnancy, and from his description of the case I had ro hesitation in concurring with him. I advised him to bring the patient in a vehicle to my private hospital as rapidly as he possibly could, whilst meantime I made all necessary preparations for immediate abdominal section. Within an hour everything was ready; the patient was found to be absolutely pulseless. She was anæsthetised. I opened the abdomen and, as one of the spectators afterwards said to me, "the rush of blood was as and blood clots, I went straight for the fundus of the uterus, and in a moment discovered that the tubal preg. nancy existed and had ruptured in the right Fallopian tube. Passing a needle swiftly into its base, I tied the broad ligament, cut off the tube and ovary, and then a little more leisurely proceeded to remove many pounds of clots and blood serum from all parts of the abdomen. I closed the abdominal wound, leaving in a drainage-tube. Not a single drop of blood was lost, and the progress of the case is briefly this. At 5 P.M. on the day of the operation the temperature was $36^{\circ}$, and no pulse could be felt save a slight flickering on deep pressure at the root of the neck. The patient's pupils were widely dilated, and did not respond to the stimulus of light. The only appearance of life was a slight movement of the nasal cartilages and of the diaphragm. Her face was a ghastly waxen yellow. By 11 P.M. the temperature had risen to $38^{\circ}$, but no pulse was perceptible, nor did the slightest flicker make its appearance till thirty-six hours after the operation, and it was fully forty-eight hours before it was possible to count it. The first record gives pulse 140 on the 22nd it came down to 126 ; on the 23rd it came down to 103; and on the morning of the 24th the temperature was $37^{\circ}$, and pulse 89 , the abdomen being perfectly flat. In the evening of the same day she passed a charac. teristic decidual membrane. She is now beginning to eat, 